\title{
Immunogenicity and protective efficacy of recombinant alkaline shock protein 23 from Staphylococcus aureus in a murine model
}

\author{
DILEEP FRANCIS, SUREKHA KUYYALIL
}

Kannur University, Thalassery, India

\begin{abstract}
The diversity and severity of infections caused and the rapid emergence of antibiotic resistance necessitates the development of a vaccine against Staphylococcus aureus. None of the antigens tried as vaccine candidates so far has been translated into a clinically viable vaccine. Recent research data suggest that antigens with the potential to activate cell mediated immunity along with humoral immunity would be the key to the development of a vaccine. Alkaline shock protein 23, a membrane-anchored protein involved in the stress response, has been identified as a $\mathrm{CD}^{+} \mathrm{T}$ cell antigen from $\mathrm{S}$. aureus. In the present study, we report the evaluation of immunogenicity and protective efficacy of a recombinant alkaline shock protein 23 from $S$. aureus in mouse models. The gene coding for the protein was cloned and expressed in Escherichia coli, purified using immobilized metal iron affinity chromatography, sequence-confirmed using mass spectrometry and intraperitoneally administered to BALB/c mice. Serum titers of $I g G, I g G 1$, and IgG2a in response to the protein were measured on post-immunization days 21, 35 and 42 using indirect ELISA and compared to control mice injected with PBS. Our results showed that the protein induced significantly higher $(p<0.01)$ antibody responses in immunized mice compared to the control mice. The mean serum antibody titers of $\operatorname{IgG}, \operatorname{IgG1}$ and $\operatorname{IgG2a}$ three weeks after the last immunization were found to be 25600, 25600 and 12800 respectively. Moreover, we found that immunization with Asp23 protected mice from a lethal dose of S. aureus strain USA30O.
\end{abstract}

Key words: Asp23, Staphylococcus aureus, $C D 4^{+}$T cell antigen, vaccine.

(Centr Eur J Immunol 2018; 43 (4): 371-377)

\section{Introduction}

The gram positive, opportunistic pathogen Staphylococcus aureus is considered to be a serious health menace due to its propensity to cause a plethora of infections, both in healthcare and community settings and the alarming pace with which it develops resistance to antibiotics [1-3]. Immunological interventions have been long sought to combat $S$. aureus infections due to the wide spread of multidrug resistant forms such as methicillin-resistant Staphylococcus aureus (MRSA) [4]. But the pursuit of a vaccine against $S$. aureus for more than two decades has not yet proven successful [5]. Many antigens were tried as vaccine candidates, but none of them translated into a completely protective vaccine [6].

It is postulated that an antigen with the ability to induce cell-mediated immune responses along with humoral immunity would be the key to develop a vaccine against $S$. aureus [7]. CD4 ${ }^{+} \mathrm{T}$ cells are critical in resolving a bacterial infection owing to their ability to produce cytokines, which can enhance the bactericidal activity of neutrophils and macrophages $[8,9]$. While it has been difficult to cor- relate the presence of high titer of staphylococcal antibodies with the clinical outcome of an infection $[10,11]$, lack of cellular immunity has been consistently correlated with increased risk of $S$. aureus infections [12-14]. Adoptive transfer of activated $\mathrm{CD}^{+} \mathrm{T}$ cells protected mice from a lethal dose of $S$. aureus but neither B-cells nor antibodies were protective [15]. For these reasons, there has been a growing interest in the identification and evaluation of $\mathrm{CD}^{+}{ }^{+} \mathrm{T}$ cell antigens from $S$. aureus.

Lawrence et al. identified a set of proteins with the ability to activate $\mathrm{CD}^{+}{ }^{+} \mathrm{T}$ cells from $S$. aureus in outbred cattle by applying a reverse vaccinology approach [16]. Among the most promising proteins identified by them was an alkaline shock protein 23 (Asp23). Asp23 (SAOUHSC_02441), a member of the Pfam DUF322 family of proteins, was first identified in S. aureus as a $23 \mathrm{kDa}$ protein that is significantly enhanced upon a $\mathrm{pH}$ upshift from 7 to 10 [17]. Later the gene coding for Asp23 was shown to be under the control of the alternate sigma factor of RNA polymerase, $\sigma \mathrm{B}$, which is a global regulator of vir-

Correspondence: Dileep Francis, Department of Biotechnology \& Microbiology, Kannur University, Thalassery, India,

e-mail: dilipfrans@gmail.com

Submitted: 14.07.2016; Accepted: 8.10.2016 
ulence genes is $S$. aureus $[18,19]$. Asp23 was also found to be the most abundant protein in growing cells of $S$. aureus with a copy number of around 25,000 per cell [20]. Asp23 was recently identified to be a membrane associated protein anchored to the cell membrane by the Asp23 membrane anchoring protein (AmaP). The protein was also suggested to have a role in cell membrane homeostasis [21].

The ability of Asp23 to act as a CD4+ $\mathrm{T}$ cell antigen, its relative abundance in growing cells, its possible role in the stress response and the subcellular localization make it an attractive vaccine candidate. In the present study, we have evaluated the immunogenicity and protective efficacy of a recombinant alkaline shock protein 23 (rAsp23) in a murine model. Alkaline shock protein was cloned and purified from $E$. coli under non-denaturing conditions. The purified protein was then used to immunize BALB/c mice. The immunized mice were challenged with a lethal dose of $S$. aureus. The results obtained suggest that $\mathrm{rAsp} 23$ is highly immunogenic in a mouse model and can protect mice from a lethal dose of $S$. aureus.

\section{Material and methods}

\section{Bacterial strains, plasmids and culture conditions}

Staphylococcus aureus strain NCTC3750 (MTCC No: 3160) was purchased from the Microbial Type Culture Center and Gene bank (MTCC), Chandigarh, India. S. aureus subsp. aureus TCH1516 (ATCC No: BAA1717, USA300 community acquired MRSA) was purchased from ATCC. Bacteria were cultured in Tryptone Soya agar (TSA) or in broth at $37^{\circ} \mathrm{C}$. E. coli strains AB5 $\alpha$ and BL21 (DE3) were routinely cultured on Luria Bertani (LB) agar or in broth at $37^{\circ} \mathrm{C}$. pJET1.2 (Fermentas) and pET28a (+) (Novagen) were used as vectors for cloning and expression. After transformation with pJET, DH5 $\alpha$ was grown in LB medium supplemented with $100 \mu \mathrm{g} / \mathrm{ml}$ of ampicillin. After transformation with pET28a (+), BL21 (DE3) was grown in LB medium supplemented with $35 \mu \mathrm{g} / \mathrm{ml}$ of kanamycin.

\section{Cloning of recombinant asp23}

Genomic DNA was isolated from S. aureus NCTC3750 using the bacterial DNA purification kit following the manufacturer's instructions (Bangalore Genei, India). The nucleotide sequence of the gene was retrieved from NCBI. Primers were designed such that the amplification product contains restriction sites for Nco I and Xho I at the 5' and 3' ends, respectively. The primers used were asp23F (5'GTTAGTCCATGGGCATGACTGTAGATAACAAT-3') and asp23R (5'-GCAGATCTCGAGTTGTAAACCTTGTCTTTC-3'). The gene was amplified by PCR in a thermal cycler (Master cycler, Eppendorf) using standard PCR conditions. The PCR product was then ligated to the sequencing vector pJET1.2 in a standard ligation reaction. The recombinant plasmid was used to transform E. coli $\mathrm{DH} 5 \alpha$. Positively transformed colonies were identified using colony PCR with gene-specific primers. The sequence of the gene insert from a positively transformed colony was determined using automated Sanger sequencing in a sequence analyzer (Model No. 3730, Applied Biosystems). After confirmation of the sequence, the gene was isolated using double restriction digestion with Nco I and Xho I followed by gel extraction of DNA. The expression vector pET28a was also double digested with Nco I and Xho I. The gene was then ligated to pET28a and transformed into E. coli DH5 $\alpha$. Positively transformed colonies were identified using colony PCR with gene-specific primers. The vector with the insert was subsequently transformed into E. coli BL21 (DE3).

\section{Expression and purification of recombinant Asp23}

The conditions for optimum expression and purification of Asp23 were determined empirically. For expression $250 \mathrm{ml}$ of LB broth was inoculated with $1 \%$ of cells grown overnight from a single transformed colony. The bacterial culture was grown until the optical density (OD) at $600 \mathrm{~nm}$ reached 0.4 . The culture was induced for the production of the protein by the addition of $1 \mathrm{mM}$ isopropyl $\beta$-D-1-thiogalactopyranoside (IPTG). The cells were collected 6 hours after the addition of IPTG by centrifugation (4000 $\times \mathrm{g}, 4^{\circ} \mathrm{C}, 20 \mathrm{~min}$ ). The pellet was resuspended in lysis buffer containing $50 \mathrm{mM} \mathrm{NaHPO}_{4}, 300 \mathrm{mM} \mathrm{NaCl}$ and $10 \mathrm{mM}$ imidazole (pH 8) and lysed by sonication. Soluble and insoluble fractions were separated by centrifugation $(6000 \times \mathrm{g}$, $4^{\circ} \mathrm{C}, 30 \mathrm{~min}$ ) and analyzed by SDS-PAGE. The protein was purified from the soluble fraction using immobilized metal ion affinity chromatography (IMAC) under non-denaturing conditions. Briefly, the clarified lysate was loaded on a column containing nickel-iminodiacetic acid (Ni-IDA) resin equilibrated with the lysis buffer. The column was washed with a solution containing $50 \mathrm{mM} \mathrm{NaHPO}, 300 \mathrm{mM}$ $\mathrm{NaCl}$ and $20 \mathrm{mM}$ imidazole ( $\mathrm{pH}$ 8). The protein was eluted using a solution containing $50 \mathrm{mM} \mathrm{NaHPO}, 300 \mathrm{mM} \mathrm{NaCl}$ and $250 \mathrm{mM}$ imidazole ( $\mathrm{pH} 8$ ). The eluate was dialyzed in phosphate buffered saline ( $\mathrm{pH} 7.4$ ) for $48 \mathrm{~h}$ with buffer changes at every $12 \mathrm{~h}$ interval. The purity of the protein was determined using SDS-PAGE.

\section{Mass spectrometric analysis}

In order to confirm that the protein purified was Asp23, MS-MS analysis was performed. Basic mass analysis and protein identification was performed using MALDI-TOF/ TOF at the Mass Spectrometry and Proteomic Core Facility, Rajiv Gandhi Centre for Biotechnology (RGCB), Kerala, India.

\section{Immunization and lethal challenge}

All animal experiments used in this study were approved by the Institutional Animal Ethics Committee (IAEC) with approval number KULS/IAEC/2013/11. All the experiments 
were carried out according to the provisions of the Committee for the Purpose of Control and Supervision of Experiments on Animals (CPCSEA), Ministry of Environment, Forests and Climate Change, Government of India.

Six-week-old female BALB/c mice $(n=12)$ were divided into two groups of 6 mice each. One group (test group) was administered with $50 \mu \mathrm{g}$ of the recombinant protein emulsified in $200 \mu$ lof complete Freund's adjuvant intraperitoneally on day zero. A booster dose containing $50 \mu \mathrm{g}$ of the recombinant protein emulsified in Freund's incomplete adjuvant was administered on day 21 . The other group (control group) received an equal volume of phosphate buffered saline (PBS) emulsified in the adjuvant on days 0 and 21. Blood samples were collected from both the groups on days 21, 35 and 42 after the first immunization by tail vein bleeding. The serum was separated by centrifugation and stored at $-20^{\circ} \mathrm{C}$ for determination of antibody titer. On day 42 both the groups were challenged with $3 \times 10^{9} \mathrm{CFU}$ of $S$. aureus TCH1516.

\section{Determination of antibody titers}

The titers of the antibodies immunoglobulin (Ig) G, $\mathrm{IgG} 1$ and $\mathrm{IgG} 2 \mathrm{a}$ in the mice sera were determined using indirect ELISA. Briefly, a 96-well microtiter plate was coated with $1 \mu \mathrm{g}$ of the recombinant protein in $200 \mu \mathrm{l}$ of coating buffer (carbonate-bicarbonate buffer, 0.1 M, pH 9.3) and incubated overnight at $4^{\circ} \mathrm{C}$. Unbound protein was washed out using PBS containing $0.05 \%$ Tween-20 (PBS-T). The wells were blocked with $400 \mu \mathrm{l}$ of blocking buffer containing $5 \%$ BSA in PBS (pH 7.4) for one hour at room temperature. The wells were washed with PBS-T. The plates were incubated with serially diluted mice sera for one hour at room temperature. The serum was removed and the plates were washed with PBS-T. Bound immunoglobulin was detected by incubating the plate with rabbit anti-mouse IgG conjugated with horseradish peroxidase (HRP) (Invitrogen) diluted $1: 2000$ in PBS-T, for 1 hour at room temperature. After washing the plates three times with PBS-T, $200 \mu \mathrm{l}$ of TMB/ $\mathrm{H}_{2} \mathrm{O}_{2}$ was added to each well and incubated in the dark for 20 minutes. The reaction was stopped by adding $50 \mu \mathrm{l}$ of $2 \mathrm{~N}$ $\mathrm{H}_{2} \mathrm{SO}_{4}$. The absorbance was read at a wavelength of $450 \mathrm{~nm}$ using a microplate reader (Model 680, Bio-Rad).

The antibody isotypes IgG1 and IgG2a were also detected using the same method as described above with some modifications. To detect IgG1 the plate was incubated with rat anti-mouse IgG1 conjugated with HRP (Invitrogen) diluted $1: 1000$ in PBS-T. To detect IgG2a the plate was incubated with rabbit anti-mouse IgG2a conjugated with HRP (Invitrogen) diluted $1: 1000$ in PBS-T.

\section{Statistical analysis}

Statistical analysis was performed using the two-sample independent $t$ test. $P$ values $<0.05$ were considered significant. All the graphing and statistical analysis were performed using OriginPro 8 software.

\section{Results}

\section{Asp23 was expressed and purified under non-denaturing conditions}

The asp 23 gene was isolated from S. aureus NCTC3750 by PCR (Fig. 1A). The sequence of the gene was verified using Sanger sequencing. The sequence of asp23 from NCTC3750 is deposited in the GenBank database under the accession number KF809672. The recombinant plasmid PET28a (+) - asp23 was constructed and used to transform into E. coli BL21 (DE3). The construct showed robust induction of asp 23 following treatment with $1 \mathrm{mM}$ IPTG at $37^{\circ} \mathrm{C}$ for 4 hours (Fig. 1B). Sonication of the induced cells followed by centrifugation and SDS-PAGE analysis revealed that a significant amount of the recombinant protein was present in the supernatant. Hence the protein was purified under non-denaturing conditions on a NiIDA column. The purified protein showed $\sim 95 \%$ purity on SDS-PAGE (Fig. 1C). MALDI-TOF analysis of the protein revealed that the purified protein had a molecular mass of $\sim 20 \mathrm{kDa}$ (Fig. 1D). Furthermore, four peptides identified using peptide mass fingerprinting (PMF) matched the sequence of Asp23 with $48 \%$ sequence coverage (data not shown). Based on these results it was confirmed that the protein purified was Asp23.

\section{Asp23 induced a strong antibody responses in BALB/c mice}

The rAsp23 specific antibody responses were determined from the sera obtained from mice belonging to the test and the control groups on days 21, 35 and 42 after initial immunizations using indirect ELISA. Results represented in Fig. 2A clearly demonstrated that the IgG responses in mice inoculated with rAsp23 were significantly higher than that in mice inoculated with PBS in the day $21(p<0.01)$, day $35(p<0.001)$ and day $42(p<0.001)$ serum. In order to reveal the type of immune response generated, the levels of antibody subclasses IgG1 and IgG2a in the sera were also determined. Both IgG1 and IgG2a levels were significantly higher $(p<0.01)$ in mice inoculated with rAsp23 compared to the control group, as represented in Fig. 2B and 2C respectively. The results also showed that the levels of IgG1 were higher than the levels of IgG2a. The serum antibody titers on days 21, 35 and 42 of the three classes of IgG were calculated from the ELISA data. The titers are shown in Table 1 and represented in Figure 2D. The antibody titers of all three antibody types increased after the booster immunization.

\section{Asp23 protects BALB/c mice from a lethal dose of $S$. aureus USA300}

In order to analyze the protective efficacy of rAsp23 in $\mathrm{BALB} / \mathrm{c}$ mice, both groups of mice were inoculated with a lethal dose of $S$. aureus USA300 three weeks after the 

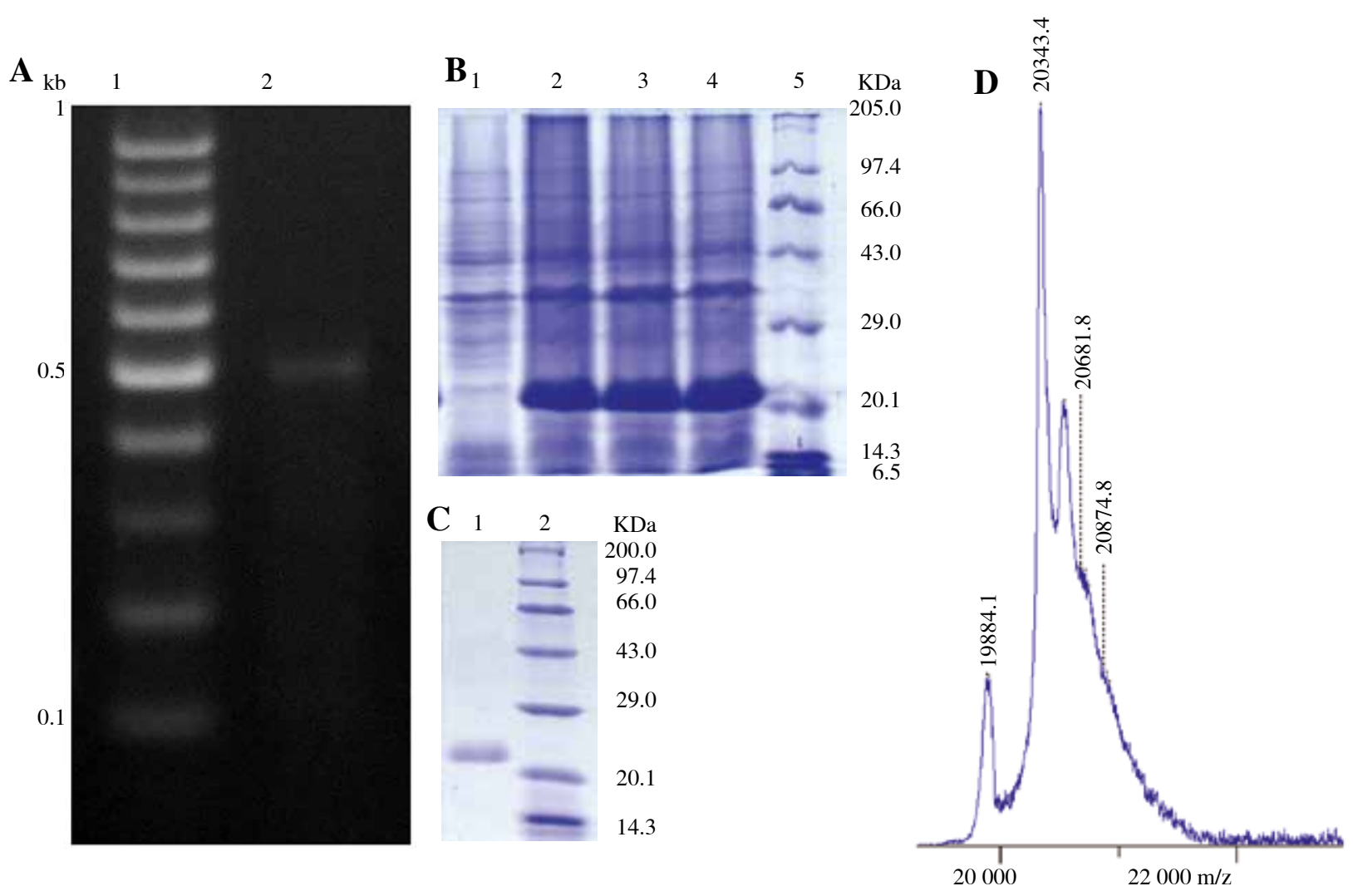

Fig. 1. Cloning, expression, purification and identification of Asp 23. The 507 bp Asp 23 gene was cloned into pET 28a (+) vector, expressed in E. coli BL21 (DE3), purified by IMAC and the protein was identified using MALDI-TOF. A) Isolation of Asp 23 gene by PCR. Lane 1, DNA marker; Lane 2, amplified asp23. B) Expression of asp23 in E. coli. Lane 1, supernatant from non-induced bacteria; Lanes 2-4, Supernatant from bacteria induced for expression of asp 23 by addition of IPTG; Lane 5, Protein marker. C) Asp23 after IMAC purification. Lane 1, Purified Asp23; Lane 2, Protein marker. D) Spectrum obtained from MALDI-TOF analysis to determine the molecular mass of purified Asp23

second immunization. The mice were monitored for 7 days after infection. Half of the mice in the PBS administered group died within 24 hours after infection. All of the mice in this group died within 2 days after infection. In contrast, all of the mice that received rAsp23 survived the lethal challenge at the end of 7 days. This result indicates that the antibody response generated by $\mathrm{rAsp} 23$ is protective against lethal dosage of $S$. aureus (Fig. 3).

\section{Discussion}

With its ability to develop resistance against virtually all antibiotics developed so far, S. aureus has become the organism least susceptible to chemotherapy. The pathogen developed resistance to methicillin, vancomycin and linezolid shortly after the introduction of each of these antibiotics [3]. Worsening the scenario, methicillin-resistant strains previously restricted to hospital settings have now emerged in the community settings [22]. Vaccination has been long envisaged as a promising therapeutic alternative to check the spread of multidrug-resistant $S$. aureus both in the hospital and community settings. Polysaccharide and protein antigens tried as vaccines so far did not prove to be completely protective in human trials [23]. A conjugate vaccine containing purified capsular polysaccharides CP5 and CP8 [24], Clumping factor A (ClfA) [25-27] and Iron surface determinant protein $\mathrm{A}$ (IsdB) [28] underwent clinical evaluation for vaccine efficacy but proved to be unsuccessful. Based on the clues obtained from earlier clinical trials and the knowledge about the host responses against $S$. aureus, it was proposed that antigens with the ability to activate $\mathrm{CD}^{+} \mathrm{T}$ cells would be the key to the development of an S. aureus vaccine [4]. In the present study we analyzed the immunogenicity and protective efficacy of Asp23, an antigen hitherto identified as a CD4 ${ }^{+} \mathrm{T}$ cell antigen. Asp23 is not a structurally and functionally characterized protein, although it is expected to play a role in the survival of S. aureus under alkaline stress [17]. S. aureus, an opportunistic commensal of the human skin, is known to establish an infection once it gains access to the tissues through wounds and abrasions [29]. Chronic non-healing wounds have an elevated alkaline $\mathrm{pH}$ compared to the surrounding skin [30]. Hence it can be suspected that Asp23 
A
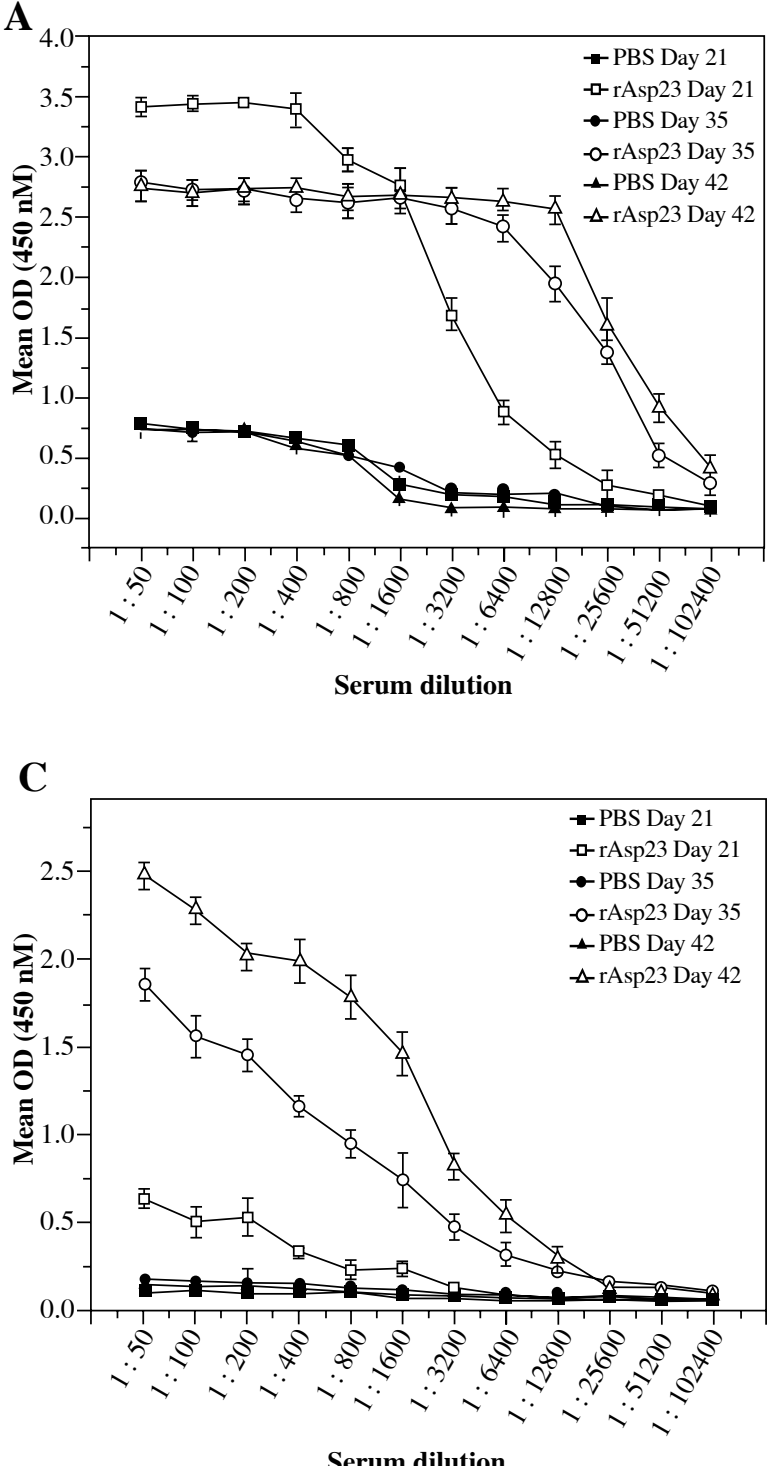

B

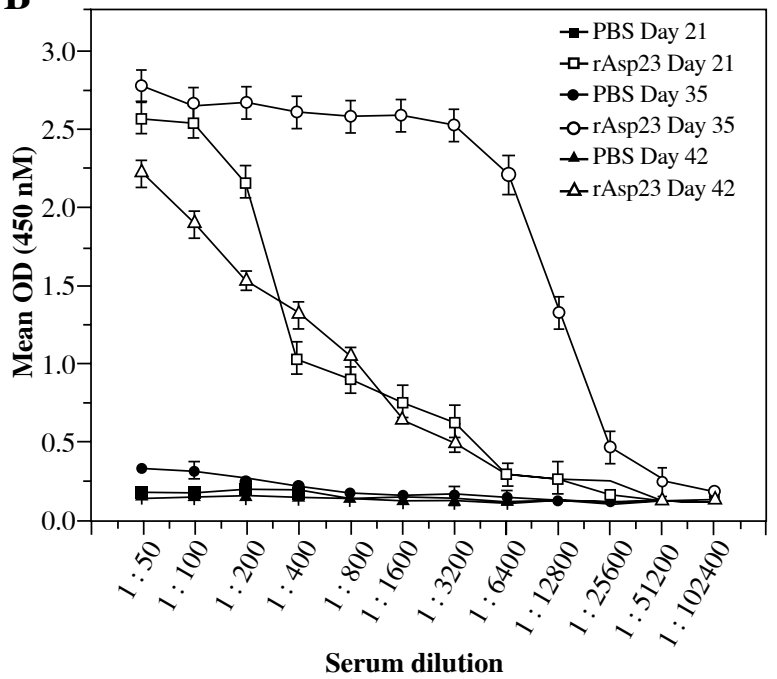

D

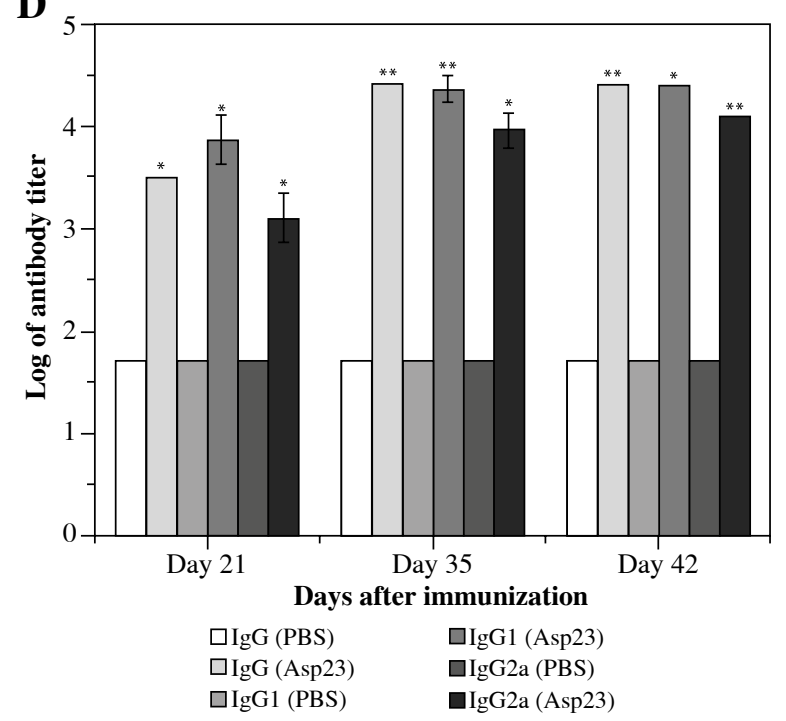

Fig. 2. Antibody responses induced by rAsp23. The antibody responses induced by rAsp23 in BALB/c mice were determined using indirect ELISA. A) Levels of IgG on days 21, 35 and 42 in mice inoculated with rAsp23 and PBS. B) Levels of IgG1. C) Levels IgG2a (D) Log titers of IgG, IgG1 and IgG2a in test and control groups ${ }^{\#}$. The error bars in each case were generated from 6 mice; asterisks represent statistical significance of differences in antibody responses of test mice compared to control mice $(* p<0.01, * * p<0.001)$

\#Antibody titers were calculated as the reciprocal of the highest serum dilution that gives an OD value greater than the cutoff OD. The cutoff OD at $450 \mathrm{nM}$ was calculated as the mean of control (mice injected with PBS) values $+3 \times$ standard deviation of the control values

Table 1. Mean antibody titers induced by rAsp23

\begin{tabular}{cccc}
\hline Days after immunization & & Antibody titer & IgG2a \\
\cline { 2 - 4 } & IgG & IgG1 & 1400 \\
\hline Day 21 & 3200 & 8000 & 9600 \\
\hline Day 35 & 25600 & 23466.67 & 12800 \\
\hline Day 42 & 25600 & 25600 & \\
\hline
\end{tabular}




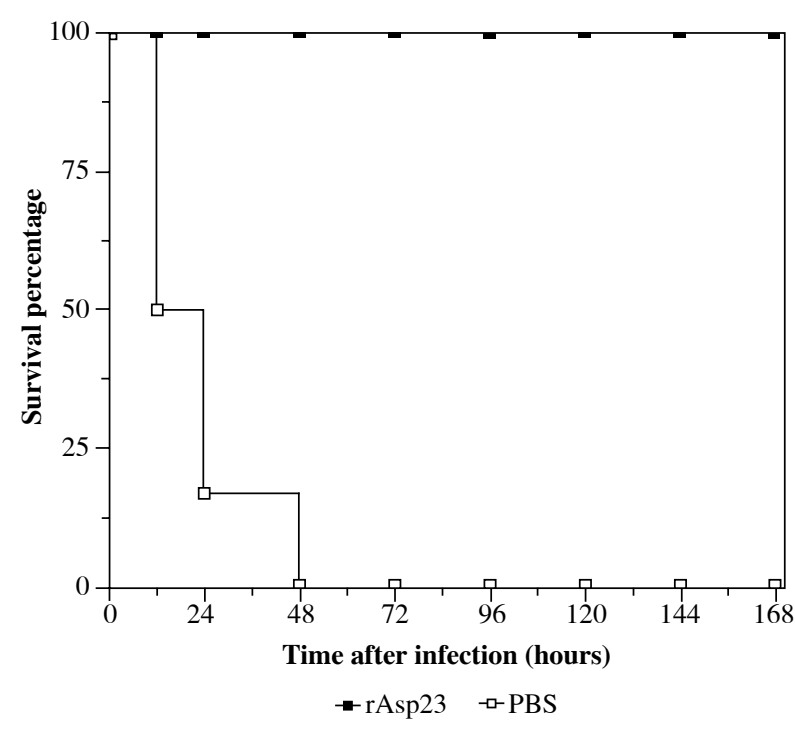

Fig. 3. Protective efficacy of rAsp23 against Staphylococcus aureus TCH1516 in BALB/c mice (Data represent observations from three independent experiments in groups of 6 mice each)

plays a role in the survival of $S$. aureus in wounds. Moreover, there are reports showing that the gene for Asp23 is under the control of the global regulator of virulence $\sigma \mathrm{B}[18,19]$. Taken together, there are reasons to assume that Asp23 is an essential virulence factor of $S$. aureus and hence an attractive vaccine candidate.

Asp23 was expressed and purified in its native form and used to immunize BALB/c mice. Indirect ELISA to quantify the protein specific antibodies in mice sera showed that there were significantly higher amounts of IgG in the mice immunized with rAsp23 compared to PBS-treated mice $(p<0.01)$ in all the three serum samples analyzed. The statistical significance of the difference in serum IgG1 concentrations between the test and control mice improved after the administration of a booster dose of rAsp23 three weeks after the initial immunization. The $p$ value for the day 21 serum was less than $0.01(p<$ $0.01)$, but in the day 35 and 42 serum it was less than 0.001 $(p<0.001)$. In order to understand the type of antibody response involved, the subclasses of $\mathrm{IgG}, \mathrm{IgG} 1$ and $\mathrm{IgG} 2 \mathrm{a}$ were also measured in the sera. Serum titers of antigen specific IgG1 and IgG2a were significantly higher in the test group compared to the control group $(p<0.01)$. Moreover, the titers of IgG1 and IgG2a increased significantly after the administration of the booster dose in test mice compared to the control mice. Although rAsp23 induced both IgG1 and IgG2a, the levels of IgG1 were higher compared to IgG2a. In mice, IgG1 is associated with a Th2type response while the induction of IgG2a is associated with a Th1-type response [31]. The optimal scenario for the clearance of a bacterial infection in humans is believed to be a well-balanced Th1 and Th2 response [32]. To check the protective efficacy of the antibody responses elicited by rAsp23, the immunized mice and the control groups were simultaneously challenged with a lethal dose of S. aureus. The challenge dose was administered on day 42 when the serum antibody titers against the protein were at the maximum, as shown in Fig. 2D. Seven days after the challenge all the mice immunized with rAsp23 survived while all the control mice succumbed to the infection. Although more studies are required to understand the mechanism of the protection afforded, this result clearly demonstrated that Asp23 induces protective antibody responses against $S$. aureus infection in mouse models. The crystal structure of the protein Asp23 has not yet been deciphered. Moreover, the exact function of the protein in vivo remains elusive. Data from such studies would help to derive a better understanding of the role played by Asp23 in S. aureus pathogenesis. Such insights would possibly lead to a better explanation of the protective immune response observed in the present study. Nevertheless, the data presented here show that Asp23 is a promising vaccine candidate that can be used alone or in combination with other potential antigens as a preventive therapeutic against $S$. aureus.

\section{Acknowledgments}

The first author acknowledges the Council for Scientific and Industrial Research (CSIR), India for financial support. The authors would like to thank the Mass Spectrometry and Proteomic Core Facility at Rajiv Gandhi Centre for Biotechnology (RGCB), Thiruvananthapuram, Kerala, India and the Inter University Centre for Bioscience (IUCB), Kannur University, Kerala, India, for facility support. Dharmanshu Shah, Arigna Bhandari and Amit Jain are acknowledged for kind help in the cloning of asp23.

The authors declare no conflict of interest.

\section{References}

1. Lowy FD (1998): Staphylococcus aureus infections. N Eng1 J Med 339: 520-532.

2. Chambers HF (2005): Community-associated MRSA - resistance and virulence converge. N Engl J Med 352: 1485-1487.

3. Chambers HF, Deleo FR (2009): Waves of resistance: Staphylococcus aureus in the antibiotic era. Nat Rev Microbiol 7: 629-641.

4. Proctor RA (2012): Is there a future for a Staphylococcus aureus vaccine? Vaccine 30: 2921-2927.

5. Thomsen I, Dudney H, Creech CB (2010): Searching for the holy grail of a staphylococcal vaccine. Hum Vaccin 6: 1068-1070.

6. Schaffer AC, Lee JC (2008): Vaccination and passive immunisation against Staphylococcus aureus. Int J Antimicrob Agents 32 Suppl 1: S71-78.

7. Fowler VG, Proctor RA (2014): Where does a Staphylococcus aureus vaccine stand? Clin Microbiol Infect 20: 66-75. 
8. Schroder K, Hertzog PJ, Ravasi T, Hume DA (2004): Interferon- $\gamma$ : an overview of signals, mechanisms and functions. J Leukoc Biol 75: 163-189.

9. Ye P, Rodriguez FH, Kanaly S, et al. (2001): Requirement of interleukin 17 receptor signaling for lung Cxc chemokine and granulocyte colony-stimulating factor expression, neutrophil recruitment, and host defense. J Exp Med 194: 519-528.

10. Verkaik NJ, Boelens HA, Vogel CP de, et al. (2010): Heterogeneity of the humoral immune response following Staphylococcus aureus bacteremia. Eur J Clin Microbiol Infect Dis 29: 509-518.

11. Kolata J, Bode LGM, Holtfreter S, et al. (2011): Distinctive patterns in the human antibody response to Staphylococcus aureus bacteremia in carriers and non-carriers. Proteomics 11: 3914-3927.

12. Laupland KB, Ross T, Gregson DB (2008): Staphylococcus aureus bloodstream infections: risk factors, outcomes, and the influence of methicillin resistance in Calgary, Canada, 20002006. J Infect Dis 198: 336-343.

13. Litjens NHR, Huisman M, van den Dorpel M, Betjes MGH (2008): Impaired immune responses and antigen-specific memory CD4+ T cells in hemodialysis patients. J Am Soc Nephrol 19: 1483-1490.

14. Wiese L, Mejer N, Schřnheyder HC, et al. (2013): A nationwide study of comorbidity and risk of reinfection after Staphylococcus aureus bacteraemia. J Infect 67: 199-205.

15. Joshi A, Pancari G, Cope L, et al. (2012): Immunization with Staphylococcus aureus iron regulated surface determinant B (IsdB) confers protection via Th17/IL17 pathway in a murine sepsis model. Hum Vaccin Immunother 8: 336-346.

16. Lawrence PK, Rokbi B, Arnaud-Barbe N, et al. (2012): CD4 $\mathrm{T}$ cell antigens from Staphylococcus aureus Newman strain identified following immunization with heat-killed bacteria. Clin Vaccine Immunol 19: 477-489.

17. Kuroda M, Ohta T, Hayashi H (1995): Isolation and the gene cloning of an alkaline shock protein in methicillin resistant Staphylococcus aureus. Biochem Biophys Res Commun 207: 978-984.

18. Gertz S, Engelmann S, Schmid R, et al. (1999): Regulation of $\sigma$ B-dependent transcription of sigB and asp23 in two different Staphylococcus aureus strains. Mol Gen Genet 261: 558-566.

19. Kullik I, Giachino P, Fuchs T (1998): Deletion of the alternative sigma factor $\sigma \mathrm{b}$ in Staphylococcus aureus reveals its function as a global regulator of virulence genes. J Bacteriol 180: 4814-4820.

20. Maass S, Sievers S, Zühlke D, et al. (2011): Efficient, global-scale quantification of absolute protein amounts by integration of targeted mass spectrometry and two-dimensional gel-based proteomics. Anal Chem 83: 2677-2684.

21. Muller M, Reiß S, Schlüter R, et al. (2014): Deletion of membrane-associated Asp23 leads to upregulation of cell wall stress genes in Staphylococcus aureus. Mol Microbiol 93: 1259-1268.

22. David MZ, Daum RS (2010): Community-associated methicillin-resistant staphylococcus aureus: epidemiology and clinical consequences of an emerging epidemic. Clin Microbiol Rev 23: 616-687.

23. Jansen KU, Girgenti DQ, Scully IL, Anderson AS (2013): Vaccine review: Staphyloccocus aureus vaccines: Problems and prospects. Vaccine 31: 2723-2730.

24. Fattom AI, Sarwar J, Ortiz A, Naso R (1996): A Staphylococcus aureus capsular polysaccharide $(\mathrm{CP})$ vaccine and $\mathrm{CP}$-spe- cific antibodies protect mice against bacterial challenge. Infect Immun 64: 1659-1665.

25. Josefsson E, Hartford O, O'Brien L, et al. (2001): Protection against experimental Staphylococcus aureus arthritis by vaccination with clumping factor $\mathrm{A}$, a novel virulence determinant. J Infect Dis 184: 1572-1580.

26. Vernachio J, Bayer AS, Le T, et al. (2003): Anti-clumping factor A immunoglobulin reduces the duration of methicillin-resistant Staphylococcus aureus bacteremia in an experimental model of infective endocarditis. Antimicrob. Agents Chemother 47: 3400-3406.

27. Josefsson E, Higgins J, Foster TJ, Tarkowski A (2008): Fibrinogen binding sites $\mathrm{P} 336$ and $\mathrm{Y} 338$ of clumping factor A are crucial for Staphylococcus aureus virulence. PLoS One 3: e2206.

28. Kuklin NA, Clark DJ, Secore S, et al. (2006): A novel Staphylococcus aureus vaccine: iron surface determinant B induces rapid antibody responses in rhesus macaques and specific increased survival in a murine $\mathrm{S}$. aureus sepsis model. Infect Immun 74: 2215-2223.

29. Lowy FD (1998): Staphylococcus aureus infections. N Engl J Med 339: 520-532.

30. Leveen HH, Falk G, Borek B, et al. (1973). Chemical acidification of wounds. An adjuvant to healing and the unfavorable action of alkalinity and ammonia. Ann Surg 178: 745-753.

31. Jansen WT, Hogenboom S, Thijssen MJ, et al. (2001): Synthetic $6 \mathrm{~B}$ di-, tri-, and tetrasaccharide-protein conjugates contain pneumococcal type $6 \mathrm{~A}$ and $6 \mathrm{~B}$ common and $6 \mathrm{~B}$-specific epitopes that elicit protective antibodies in mice. Infect Immun 69: 787-793.

32. Berger A (2000): Th1 and Th2 responses: what are they? BMJ 321: 424. 